\title{
GESTÃO DEMOCRÁTICA E AVALIAÇÃO EM UMA ESCOLA DE NITERÓI, RJ: REFLETINDO SOBRE UM ESPAÇO DE POSSIBILIDADES \\ DEMOCRATIC MANAGEMENT AND EVALUATION IN A SCHOOL OF NITERÓI, RJ: REFLECTING ON A SPACE OF POSSIBILITIES
}

\author{
Gloria Maria Anselmo de Souza ${ }^{36}$ \\ Waldeck Carneiro ${ }^{37}$ \\ Helena Amaral da Fontoura ${ }^{38}$
}

\section{Resumo}

O artigo, parte integrante da tese de doutorado defendida em 2016, recupera algumas das problematizações que se organizaram em torno das discussões sobre gestão democrática e avaliação escolar a partir de uma perspectiva emancipatória. 0 movimento aqui apresentado se articula em torno da escuta das gestoras e das pedagogas sobre $o$ tema. As reflexões trazem pistas importantes para compreendermos o ponto de interseção entre estes dois conceitos materializados no contexto escola em seu dia-a-dia.

Palavras-chave: Gestão democrática. Avaliação. Emancipação.

\begin{abstract}
This article, an integral part of the doctoral thesis defended in 2016, recovers some of the problematizations that have been organized around the discussions about democratic management and school evaluation from an emancipatory perspective. The movement presented here revolves around listening to managers and pedagogues on the subject. The reflections bring important clues to understand the point of intersection between these two concepts materialized in the school context in their daily life.
\end{abstract}

Keywords: Democratic management. Evaluation. Emancipation.

\footnotetext{
${ }^{36}$ Doutora e Mestre em Educação, pela UFF. Supervisora Educacional da Rede Municipal de Niterói. Coordenadora do PNAC. (SEMECT/FME - GRUPPE (UFF). E-mail: gloriaanselmo50@gmail.com

${ }^{37}$ Professor Doutor Associado - Universidade Federal Fluminense. Coordenador do GRUPPE. Deputado Estadual/RJ. E-mail: waldeckcarneiro@gmail.com

${ }^{38}$ Pós-Doutora em Educação pela UFMT. Professora e pesquisadora da UERJ-FFP. Pesquisadora do CNPq. E-mail: helenafontoura@gmail.com
} 


\section{RevistAleph}

\section{Introdução}

Este artigo é parte de uma tese de doutorado intitulada Avaliação Emancipatória e Gestão Democrática: caminhos para uma escola transformadora no município de Niterói/RJ, apresentada na Universidade Federal Fluminense em 2016. Nosso recorte aqui traz o aporte da Gestão Democrática, na voz do grupo gestor da escola que se configurou como campo de pesquisa.

Refletimos inclusive com relação a processos avaliativos e suas implicações no espaço escolar, à luz das percepções de participantes envolvidos na investigação em tela. Trazemos falas da diretora, da diretora adjunta, da supervisora e da orientadora educacional, muito embora estas duas habilitações estejam fundidas no cargo de pedagogo, conforme Plano de Cargos e Salários da Rede Municipal de Educação.

Paro (2001; 2008a 2008b), Dourado (2012; 2006), Najjar (2006) e Bastos (2000) nos ajudaram a pensar esse trabalho. Destas valiosas contribuições destacamos os apontamentos de Dourado (2006), quando afirma que uma gestão democrática implica na busca e efetivação de processos embasados em uma dinâmica que os compreenda coletivos, se organize e pratique uma gestão alicerçada em princípios participativos de decisões. Trabalhar sob a orientação de princípios de gestão democrática implica a efetivação de outros processos organizativos que não os habitualmente presentes na instituição escola, e para tal sua implementação nem sempre é fácil ou rápida, menos ainda naturalizada. Sabemos que a participação é um processo complexo, de múltiplas facetas e que acontece em níveis distintos, o que significa que não há uma linearidade nem uma única forma de acontecer. O autor aponta que "várias dinâmicas se caracterizam por um processo de participação tutelada, restrita e funcional; outras por efetivar processos coletivos, inovadores de escolha e decisão" (DOURADO, 2006, p. $60)$.

Spósito (2000) nos contempla com reflexões sobre participação popular, apontando alguns pressupostos que nos interessa sinalizar. A autora fala de uma abordagem do referido conceito que se materializa sob a ótica da tutela. A questão da participação é um aspecto que data do início do século XX e estava, segundo a autora, ligada às iniciativas sanitárias, melhoria do nível de higiene e saúde das populações menos favorecidas, além de despertar a educação moral e cívica, podendo assim trazer aspectos de "moralização de costumes", desempenhando um papel disciplinador a ser 


\section{RevistAleph}

estendido às famílias, reforçada com a criação das Associações de Pais e Mestres, o que a autora chama de "cidadania sob controle" (idem, p.8).

Fernandes (2014), ao destacar a importância da avaliação, nos orienta que a compreensão dessa dinâmica é um processo e não uma medida ou um produto, que ainda precisa ser construída. A ideia de avaliar para aprender ainda está em construção. Há um descompasso entre discursos e práticas. Para a autora, tanto a organização quanto a forma como os estudantes caminham são processos construídos e de tomada de decisões, ligados à concepção de escola e sua função social, o que implica diretamente na concepção de avaliação e nas práticas efetivadas nos espaços escolares.

A primeira participante entrevistada foi diretora da escola campo da pesquisa, que relatou algumas conquistas e desafios encontrados no início da gestão em relação aos pais. Segundo ela, no início os responsáveis eram arredios, custavam a aparecer, a falar, seu comportamento demonstrava um sentimento de inferioridade e o silêncio marcava o diálogo com a direção. Mas durante a entrevista ficou aparente um cuidado na relação travada com a comunidade escolar. Em suas palavras:

Eu acho que é falta de costume também. A gente se acostuma com essa situação. Então assim, hoje eu percebo os pais superparticipativos, temos uma relação muito boa (...) alguns deles eu já tive até como parceiros, porque o meu filho mais velho estudou aqui até completar o 5o ano. Tenho uma relação com pais, que eu convivia com eles os dois lados, como a diretora e como a mãe.

A problematização aqui levantada nos aponta os limites que constituem o conceito de participação, historicamente perseguindo esta mesma lógica que ainda assombra os princípios da gestão democrática nos dias atuais. Na maioria das escolas brasileiras esta é a concepção presente, a de que os responsáveis se apresentam como seres passivos, sem vez ou voz. E onde este espaço lhes é concedido, não sabem muito bem o que fazer com a autonomia e o direito que Ihes cabe nessa dinâmica. Por isso, continuam, em maioria, calados, obedientes, disciplinados e tutelados pela direção das escolas. Nem o fato de a diretora ser mãe também na unidade escolar, demonstrando credibilidade na escola pública, cria uma simetria nas relações.

Relato de campo: 


\section{RevistAleph}

Era março de 2015. Em um dos momentos de pesquisa fomos convidados a participar de uma assembleia do Conselho EscolaComunidade da E.M. Lucia Maria Silveira Rocha. A pauta versava a respeito de esclarecimentos sobre o que representa o conselho escola-comunidade, suas atribuições; problemas no fornecimento de energia elétrica enfrentados pela escola; horários de entrada e saída dos turnos; faltas; IDEB; o que comprar com a verba; a reclamação das professoras sobre as impressoras. Havia também um item que tratava da utilização da verba da escola. Cerca de trinta responsáveis no auditório. Então a diretora deu alguns informes e comunicou aos presentes que havia um determinado valor que fora arrecadado. Uma das mães se pronunciou concordando que o problema era delicado. Outros responsáveis comentaram a observação e havia concordância sobre a aplicação do dinheiro. Então a diretora indagou aos responsáveis se concordavam com a compra das impressoras. Não houve manifestações contrárias, ficando então decidido que a verba teria este fim. A conversa foi clara, objetiva e acolhedora. Houve comentários sobre a reforma do prédio destinado à Educação Infantil. Sem mais pronunciamentos, a reunião foi encerrada e registrada em ata.

Considerando estes momentos, é possível perceber que ainda há alguns passos a serem dados no campo da participação da comunidade no processo decisório. Pareceu-nos que não houve uma discussão antes da tomada de decisão. Os responsáveis, talvez por confiança, acolheram a proposta de compra das impressoras. Talvez notificar a existência da verba e pensar com eles o destino dela fosse um processo mais democrático. Tal reflexão se coaduna com a questão apontada por Spósito (2000) sobre a relação entre representantes e representados. Os representados, em certos momentos, assumem posições pacíficas. Não problematizam, não fazem contrapropostas. Enfim, não conseguem participar efetivamente das decisões da escola. Embora a gestão seja solícita, dialogada, as famílias ainda não têm a voz que poderiam ter. Uma voz potente, crítica e reflexiva. Uma voz que se coadune com os princípios da gestão democrática.

Consultando os estudos de Dourado (2012), é possível perceber que a postura da direção procura incorporar a compreensão de que não necessariamente a participação deve ser padronizada, já que é um conceito polissêmico, de diferentes significados quanto à natureza, finalidade, ou alcance do ideal de aprendizagem cidadã.

A entrevistada retoma a reflexão apontando que este é um processo em construção e volta a se referir à sua relação com os responsáveis: 


\section{RevistAleph}

Eu tenho os pais representantes, a dificuldade que era no início para tirar os dois pais para representar os pais. $O$ medo que eles tinham de representar o segmento deles. Era muito difícil e nas reuniões pra conquistar esse pai para que ele pudesse falar, que fosse porta-voz. Entender que era porta-voz do grupo e que precisava falar, para que a gente pudesse entender o que aquele grupo queria. Como foi difícil, como foi complicado.

Sua fala indica o quanto tem se preocupado em trazer a comunidade para dentro da escola, mas as pessoas parecem não estar acostumadas a esse tipo de envolvimento. Como ultrapassar estas barreiras historicamente construídas, onde alguns têm voz e outros, e muitos, não se sentem com direito a ela? As reflexões de Dourado (2006) talvez sejam alternativas para explicar as dificuldades encontradas pelas diretoras em busca da conquista dos responsáveis nos processos de participação. A E. M. Professora Lúcia Maria Silveira Rocha contava em 2016 com trezentos e cinquenta e nove (359) estudantes matriculados no 10 e 20 ciclos do ensino fundamental de 10 e 2 o ciclos, mais cinquenta e oito (58) crianças nos diferentes anos do Ciclo Infantil, totalizando quatrocentos e dezessete (417) matrículas no ano em curso, conforme dados da Assessoria de Estudos e Pesquisas Educacionais $(\mathrm{AEPE} / \mathrm{FME})^{39}$.

A unidade escolar, localizada em Jurujuba, comunidade às margens da Baía de Guanabara, possui uma população de cerca de dois mil e oitocentos (2.800) habitantes ${ }^{40}$, maioria formada por adultos e idosos, muitos deles responsáveis pelos estudantes, e se encontram ainda na categoria de analfabetos funcionais. Diante do desafio de aproximar a comunidade escolar do processo de gestão é possível considerar que a equipe gestora estava, no momento de nossa pesquisa, em fase de indagações sobre qual seria a lógica de participação mais adequada às necessidades daquela comunidade, formada por pescadores, comerciantes, trabalhadores informais, empregadas domésticas e a diretora geral da escola, na condição de mãe de ex-aluno e aluno do 1 을 ciclo, atualmente.

No que refere às questões pedagógicas, a diretora é uma figura muito presente.

Está sempre atenta às questões dos professores e dialoga continuamente com as pedagogas. As relações, segundo ela, já não são fáceis e estão em permanente

\footnotetext{
${ }^{39}$ Dados levantados junto à AEPE nos meses de Dezembro/2016 e janeiro/2017.

${ }^{40}$ Disponível em:http://populacao-jurujuba_niteroi.html. Acesso em 05/02/2017.
} 


\section{RevistAleph}

construção. Quem nos ajuda a compreender este segundo aspecto é Morin (2002) quando afirma que

é preciso substituir a visão na qual este universo é o jogo e o risco da dialógica (relação ao mesmo tempo antagônica, concorrente e complementar) entre a ordem, a desordem e a organização (p. 63-4).

A postura da diretora tem um comportamento marcado pela dialogicidade e pela dialética, ou seja, ouve, acolhe, discorda, problematiza frente às dificuldades/complexidades que a contemporaneidade traz consigo, que estão presentes ou adentram a escola. Participação nos planejamentos, mediação de conflitos, escuta atenta, dentre outras ações que se configuram como demandas cada vez mais diversas e desafiadoras. Afirma que assume grupos de referência constantemente para garantir um terço de planejamento dos professores quando não há especialistas ou algum professor tira licença garantida pela Lei Municipal $\mathrm{n}$.으 $809 / 1990^{41}$, que além de tratar do aumento do funcionalismo, incluiu em seu texto, no artigo 11, o direito a um dia de falta abonada no mês em curso. Destaca ainda o bom relacionamento que tem com os alunos e a possibilidade de, nesses momentos, observar e avaliar como as crianças estão se desenvolvendo e aprendendo. E completa, referindo-se à avaliação:

A avaliação praticada na escola é contínua e processual, diz ela: "a gente está sempre avaliando qualquer trabalho, qualquer conversa (...) nossas práticas e o aluno". Relembra que, no decorrer de 2014, perceberam que faltava algo. Apenas a avaliação diagnóstica não se apresentava como suficiente para direcionar o trabalho pedagógico e as aprendizagens necessárias. Resolveu-se, assim incluir outras propostas: "Então, assim, hoje a escola adota a avaliação formal também". Indagada sobre o que chama de avaliação formal, a diretora esclarece que se refere à prova e acrescenta:

A gente trabalha sim com prova, trabalha com avaliação. Vamos supor, a gente fez o planejamento, articulou o nosso semestre, o nosso trimestre (...) o professor passou "pra" gente, entramos na sala, mas e aí? $O$ que de fato a gente acha que aquilo serviu? Vamos ver como está esse aluno? Vamos conversar.

\footnotetext{
${ }^{41}$ LEI № 809, DE 27/03/1990 - PUB. ÓRGÃO OFICIAL, DE 28/03/1990. AUMENTO DO FUNCIONALISMO MUNICIPAL DE NITERÓI MARÇO/90. Artigo 11, § 2‥ Disponível Em: Leis municipais.com.br. Acesso Em 28/04/2016.
} 


\section{RevistAleph}

Percebemos que a diretora se apresentou um tanto desconfortável em declarar que adota a prova como instrumento de avaliação. Os gestos, a fala entrecortada, a postura tensa pareciam revelar o conflito que travava consigo em revelar esta faceta da escola. Essa postura mostra o caráter constrangedor que envolve a prova escrita para aqueles que estão em processo de mudança, aqueles que estão buscando alternativas para conduzir o processo educativo/avaliativo.

As inquietações da gestora podem estar inscritas naquilo que Santos (2000) identifica como crise paradigmática e Morin (2002) qualificará como cegueiras paradigmáticas. Dito por ela mesma tem procurado abandonar determinadas concepções e caminhando para outras, a partir de um movimento bastante complexo, uma vez que o já conhecido é o lugar das certezas e do conforto que nem sempre se apresenta satisfatório diante das exigências atuais no campo educacional. Enquanto isso, a mudança inquieta, deixa dúvidas, rouba o chão. É algo que vai abandonando a dominação, e busca caminhar para a emergência, em direção à insurgência e à ruptura.

Retomando as reflexões de Morin (2002), esta atora social se joga também na zona invisível dos paradigmas, os quais selecionam e determinam a conceptualização das operações lógicas, designam as categorias de sua inteligibilidade e controlam seu emprego, ou seja, regulam o modo de agir, conhecer e pensar dos indivíduos. Este autor sinaliza com duas definições de paradigmas: promoção/seleção dos conceitosmestres da inteligibilidade, determinação das operações lógicas-mestras. (idem, p. 24 25).

A diretora vive momentos de conflito cognitivo e profissional, está em processo de mudanças frente às demandas da contemporaneidade trazidas pela sociedade atual e que interferem diretamente na formação de crianças e adolescentes. Já percebe que precisa mergulhar em novas trajetórias, hesita, vacila, mas vai em frente. Erra, acerta, escuta, mas não desiste para retomar os lugares de conforto. Segue no processo de mudança. Continuando seu depoimento procura explicar como a avaliação se materializa no cotidiano da escola: 


\section{RevistAleph}

A gente tem período de prova, a gente tem avaliação e a gente estuda. Quando faz as provas não simplesmente por fazer, a gente pega mais do que o resultado do aluno e procura ver o que está acontecendo naquela turma. Vamos supor, tem 20 questões discursivas e quase todos erram a questão tal. Então, peraí, houve falha nossa (...). Então, vamos rever o que a gente fez? Porque eu acho que o mais importante da avaliação é o feedback, não é?(...) o que a gente precisa melhorar, então, a gente faz sim. Desde 2010 estamos trabalhando dessa maneira.

Explica o processo de construção, aplicação, análise de desdobramentos adotados em relação à prova, esclarecendo como este instrumento ajuda a organizar e dinamizar a aprendizagem dos estudantes e o trabalho pedagógico na escola. Aparentemente, sua caminhada aponta para duas abordagens diferentes, mas complementares: a primeira, ancorada na ideia de avaliação diagnóstica defendida por Luckesi (2002) e Hoffmann (2003). Segundo estes autores, a avaliação diagnóstica aponta lacunas, possíveis caminhos e demandas a serem superadas no processo pedagógico.

A segunda abordagem, parte de outro patamar, defendido por Perrenoud (2000), que o autor denomina formativa, aquela que vai se dando ao longo do processo. Se considerarmos a trajetória que a escola vem fazendo pelo olhar/sentir da diretora, é possível vislumbrar um processo que se configura a favor dos estudantes. Ressalta ainda que o dever de casa faz parte da rotina escolar e o classifica com uma das formas de avaliação, mas esclarece aos pais que o dever de casa não é tarefa deles. E completa:

Boa parte dos pais aqui são pessoas analfabetas. Então, na medida do possível ela [a família] pode ajudar sim, arranjando um jornal (...) mas a criança tem que estar levando uma coisa que ela sabe fazer (...) Se ela chegou a casa e teve dificuldade, não conseguiu, então alguma coisa está errada. Então, a gente tem que começar a observar por que aqueles alunos não estão trazendo o trabalho [de casa].

A diretora destaca a importância da participação familiar, sem isentar tais atores sociais da responsabilidade de acompanhar a vida das crianças na escola, mesmo tendo clareza das limitações presentes ao seu processo de escolarização. Durante os momentos que estivemos na escola durante a pesquisa, tivemos a oportunidade de observar a circulação de responsáveis pelos estudantes. Pessoas humildes, pobres, muitas negras. Aparentemente, a maioria dessas pessoas não 


\section{RevistAleph}

demonstrava uma formação escolar elevada. Como as conhece melhor, a preocupação da diretora procede. Imputar aos estudantes e a suas famílias uma grande responsabilidade com o dever de casa seria uma injustiça. No entanto, usar esta ferramenta pedagógica para criar vínculos de aproximação entre estudantes responsáveis - escola nos parece uma estratégia significativa, uma vez que o acompanhamento da vida escolar das crianças e adolescentes é uma prerrogativa legal importante, além de contribuir para o fortalecimento dos processos de gestão democrática.

Ao mesmo tempo, a dificuldade com o dever de casa também alerta para possíveis lacunas no trabalho pedagógico. O que a conversa vai sinalizando é uma postura comprometida com o desenvolvimento integral dos estudantes, pela sua autonomia e emancipação, no sentido freireano dos termos. Além disso, esta declaração aponta pistas para a necessidade de uma política educacional voltada para a educação de jovens e adultos na região.

Entramos, então, na seara das avaliações externas. No início da conversa a diretora mencionou que a escola estava implicada nas avaliações externas estabelecidas pelo Ministério da Educação (MEC), a saber: Provinha Brasil, ANA (Avaliação Nacional da Alfabetização) e Prova Brasil, frutos do SAEB (Sistema de Avaliação da Educação Básica). O município de Niterói é signatário na adoção desses três exames nacionais. Além disso, em 2014, a Fundação Municipal de Educação instituiu também o SAEN (Sistema de Avaliação da Educação de Niterói). E sobre o assunto, a diretora declarou:

Eu acho fundamental. (...) não gosto dessa coisa de ranking, acho que não tem nada a ver, a gente não está aqui para disputar com ninguém, até porque trabalhamos dentro da mesma rede, com os mesmos objetivos. Mas eu acho por questão de você mesmo se avaliar, que uma coisa é eu dar uma avaliação com meu professor dando prova para o aluno dele, outra coisa é ter outro profissional que, às vezes, nem é da escola dar essa prova. E assim, o que acho interessante, que às vezes faço até crítica à própria Fundação, a falta do feedback.

Aqui a diretora se expressa dividida entre duas perspectivas sinalizadas por Fernandes (2014): a primeira refere-se às avaliações externas, que são apresentadas 


\section{RevistAleph}

pelos sistemas como forma de melhorar o ensino, e a segunda que trata das práticas engendradas no cotidiano das escolas.

Esta dualidade se apresenta como uma marca histórica que coloca em jogo a questão da qualidade que promove inquietações, desassossegos, posto que ainda não é possível identificar com clareza o caminho mais adequado e justo para avaliar e caracterizar o que seria melhor para as aprendizagens e avanços dos estudantes, confirmando a presença de uma crise paradigmática anunciada por Santos (1987), que a descreve como um modelo de racionalidade científica em crise, de caráter profundo e irreversível, matriz inicial de uma revolução científica. A crise paradigmática cria zonas de desconforto, instabilidade e incertezas, mas apresenta-se ainda de maneira germinal anunciando um paradigma que chama de emergente, definido como algo totalmente distinto do paradigma dominante, para ele ainda em vigor.

Referindo-se à dimensão Avaliação das Aprendizagens, materializada na aplicação da prova Avaliar para Conhecer, a diretora critica a maneira como foram encaminhados os relatórios de análise de dados levantados após a aplicação da prova, além de se queixar de certa omissão na problematização dos resultados encaminhados pela equipe gestora da FME, sem quaisquer problematizações ou encaminhamentos que ajudassem a escola a repensar suas práticas pedagógicas. Segundo ela, tal procedimento reduz a importância do exame externo à escola e só cria mais demandas ao cotidiano. Embora esta entrevista seja rica de elementos passiveis de problematização, optamos por avançar para outras reflexões com vistas ao aprofundamento das discussões.

No processo, seguimos dialogando com diretora adjunta da unidade escolar. Ela está na gestão desde que a atual direção geral assumiu a escola. Durante os primeiros encontros, pudemos observar uma postura afetuosa, divertida e muito camarada com todos os profissionais da escola. O envolvimento afetuoso se estendia aos estudantes que a saudavam com gestos carinhosos. Vale ressaltar que todas as vezes que estivemos na escola nunca percebemos nenhuma atitude explícita ou dissimulada de animosidade ou de falta de respeito com quem quer que fosse à escola. Ao contrário, as posturas eram francas, firmes, mas caracteristicamente educativas. A cozinha é um dos redutos favoritos da adjunta. Entrava, cumprimentava, conversava sobre os quitutes que seriam servidos. Conversava sobre as vidas com as merendeiras e depois 


\section{RevistAleph}

seguia para a sala da direção. Nessa caminhada, passava nas salas de aula cumprimentando professores e alunos.

Iniciamos a entrevista com um resgate de sua trajetória profissional. A adjunta sempre estudou em escola de freiras e começou sua carreira profissional em 1985, na rede municipal do Rio de Janeiro. Segundo ela, foi um choque de realidade. Começou a trabalhar em Vila Kennedy, bairro localizado às margens da Avenida Brasil, próxima ao bairro de Bangu na zona oeste da cidade. Ela relata:

Fui inserida no mundo da vida de comunidade e da escola pública que eu desconhecia que eu aprendi na prática. (...) saí do curso Normal acostumada com aquelas crianças que prontamente aprendiam. E o meu choque com a escola pública em plena favela. Favela de 1985 não é favela de agora, né? Era favela sem nada, era uma comunidade pobre, eu achava que aquilo não dava conta.

A diretora adjunta se referia à sua formação inicial que não era suficiente para atender às demandas das classes populares. Inicialmente, relembramos vários estudos sobre formação de professores que apontam que se trata de um processo permanente. Lembrando Paulo Freire, é possível perceber nas reflexões da adjunta que ensinar exige a consciência do inacabamento. Com este autor, encontramos na fala da diretora adjunta, pistas de que:

Como professor crítico, sou um "aventureiro" responsável, disposto à mudança, à aceitação do diferente. Nada do que experimentei em minha atividade docente deve necessariamente repetir-se. Repito, porém como inevitável, a franquia de mim mesmo, radical, diante dos outros e do mundo. Minha franquia ante os outros e o mundo mesmo e a maneira radical como me experimento enquanto ser cultural, histórico, inacabado e consciente do inacabamento (FREIRE, 1996, p. 50).

A gestora se olha e se percebe como alguém que ainda não sabe como lidar com crianças de classe popular. Reflete sobre sua prática e vai buscar outros caminhos para enfrentar o novo desafio. Em sua entrevista relata uma mudança de percurso quando abandona o curso de Pedagogia e vai buscar nos estudos adicionais de alfabetização alternativas para trabalhar com os alunos de Vila Kennedy. Na sua fala também aparecem indícios do antigo processo de desvalorização do magistério quando que destaca que: "_ tinha dois empregos, eu era professora e para lá e para cá, era mãe "maratonista". Nessas idas e vindas, a diretora foi se constituindo uma 


\section{RevistAleph}

profissional competente, implicada e comprometida com os alunos mais pobres. $\mathrm{O}$ inacabamento do ser ou a sua inconclusão, como afirma Freire (1996), é próprio da experiência vital. Onde há vida, há inacabamento. Mas só entre homens e mulheres o inacabamento se tornou consciente.

O discurso aponta para um movimento que olha de modo sensível e respeitoso os alunos da escola que dirige. Entra em embates. Argumenta, ensina, aprende e cresce demonstrando que acredita em uma educação que liberta e em uma gestão que pode ser mais democrática. Sobre o 'conhecimento escondido', a diretora percebe os indícios da exclusão social e educacional que os alunos da escola pública enfrentam em suas trajetórias escolares e de vida, uma experiência de negação e invisibilidade muito comum na sociedade brasileira, há muito tempo, quando se trata das populações menos favorecidas. Outro aspecto que nos chamou a atenção no seu depoimento:

Você foi se acostumando com aquela vivência da escola pública que as outras pessoas não têm conhecimento. Parece um conhecimento escondido (...) você vai conversar com as pessoas, principalmente nessa época de eleição e, aí, as pessoas falam alguma coisa, eu falo assim:_Mas você vivencia, conhece o que é vivência de comunidade? Você sabe o que é uma criança que não tem banheiro em casa? Já pensou na sua vida e não ter banheiro?

Tal reflexão sinaliza uma preocupação com o humano, com as precárias condições de vida da população prioritariamente frequentadora da escola pública e de inestimável valor. A diretora adjunta acredita no diálogo, na sensibilidade e no

profissionalismo. E afirma: "_É nesse diálogo com o outro que eu aprendo a me mudar".

Enquanto conduzimos a entrevista vamos observando gestos, movimentos corporais, tons da voz e não identificamos discursos ensaiados, posturas disfarçadas. Ao contrário, a conversa é marcada por sinceridade/simplicidade a partir de muitos exemplos concretos de diálogos com a comunidade que não se limitam a retratar as rotinas cotidianas, mas estão marcadas por interações, confidências e desejo de intervir a favor dos estudantes e da comunidade escolar, além de se tornar uma pessoa e profissional melhor. E este modus operandi não se restringe aos estudantes e seus responsáveis. Em seu depoimento, as reflexões abarcam professores e demais profissionais de educação. 


\section{RevistAleph}

Avançando, encaminhamos nossa conversa sobre avaliação. A diretora adjunta declara que provas e testes são medidas, o que a leva a não ter preocupação com a avaliação formal. Ela recupera momentos da formação acadêmica em que estudava um componente curricular chamado Medidas Educacionais e Avaliação e esta memória não a incomoda, já que construiu uma concepção pedagógica que ultrapassa a lógica conservadora dos anos 1970/1980 quando se tornou professora e pedagoga. Então declara:

Algumas coisas que a gente chama de avaliação são medidas. Testes não sabem o quê... Para mim são medidas. A avaliação eu faço ao longo do processo. Eu falo para elas [as professoras]: "_ eu não preciso estar dentro da sala de aula para avaliar o que está acontecendo". Porque diferentemente das pedagogas, vou toda hora à sala de aula. Para falar com aluno, dar recado a professora. Assim tenho um olhar amplo. Então, às vezes chego para a pedagoga: Olha só sei o que ela está dando na sala de aula, porque vejo o que ela passa no quadro. Eu vejo o que acontece dia-a-dia. Então, para mim, essa avaliação mais é importante do que o resultado de um teste.

A avaliação tem uma dimensão ressignificada em seu discurso. O olhar/sentir, formado na vida, mas também marcado pelas discussões sobre a organização escolar em ciclos que atravessaram o período de 2000 - 2009 na rede municipal de educação de Niterói, dentre outros, Ihe permite uma compreensão ampliada sobre o tema da avaliação. Está atenta ao processo avaliativo que se materializa na unidade escolar, dialoga com a equipe pedagógica, com a equipe docente e com os responsáveis. Os depoimentos da diretora adjunta estão intimamente associados a estas reflexões. Ela defende que há concepções em jogo e precisamos estar atentos, dialogar, problematizar. Senão, o que prevalece é o que há de mais conservador e tradicional. Cuida inclusive, de alertar as professoras sobre tais movimentos e concepções.

A equipe pedagógica tem um papel importante e articulador junto à gestão e aos responsáveis. Por isso dialogamos também com as pedagogas da unidade escolar. Iniciamos pela mais jovem que, atualmente, já não se encontra mais na escola. Feito o convite, a mesma aceitou de pronto. Tranquila, mas aparentando ser pouco inexperiente, a pedagoga se descontraiu e a entrevista começou. Fez um breve resumo de sua trajetória profissional. Uma questão inicial que me chamou a atenção foi a declaração de que estava vivendo uma experiência inicial como pedagoga concursada. 


\section{RevistAleph}

E quando eu vim para cá comecei a ver o outro lado, às vezes quando a gente está em sala de aula não consegue ter dimensão do trabalho da gestão. Me encantei porque gosto. Também percebi que os problemas aumentam quando estamos na gestão. ... em sala de aula parece que nosso mundinho é só a nossa sala. E... esquece de que a escola é tudo. É a merendeira, a auxiliar de serviços gerais, o pessoal da secretaria. E estou gostando do nosso papel.

Esta primeira conversa já anuncia um posicionamento reflexivo, crítico e fundado na coletividade. No entanto, não se pode ignorar a pouca experiência no cargo de pedagoga. A comparação entre a sala de aula e a gestão da escola também nos chama a atenção. Ela evidencia a necessidade de estudos mais aprofundados sobre gestão escolar na formação de professores. Luiz Fernandes Dourado ${ }^{42}$, argumenta que esta área de conhecimento deveria ser matéria obrigatória em todos os currículos de licenciatura e pedagogia, com vista a permitir que os graduandos pudessem ter uma visão ampliada sobre a dinâmica da escola como um todo.

Os processos formativos demandam cada vez mais um olhar ampliado sobre os diversos movimentos que dinamizam a escola, a fim de criar as condições mínimas para atuação dos profissionais de educação que nela circulam. Isso envolve gestão democrática, mediação de conflitos, ressignificação das metodologias e práticas pedagógicas, além de outros aspectos já conhecidos pelos educadores que formam outros educadores. Retomamos Paulo Freire (1996) para destacar que existem saberes necessários à prática docente que não podem ser desconsiderados. Inicialmente, considerar que "não há docência sem discência", ou seja, nossa profissão depende visceralmente da existência de estudantes.

Além disso, reconhecer que ensinar exige risco, aceitação do novo e rejeição a qualquer forma de discriminação, exige também pesquisa, reflexão crítica sobre a prática e consciência do inacabamento. Exige também comprometimento, coragem para intervir no mundo, reconhecimento das ideologias presentes e, fundamentalmente, que a mudança é possível.

São lições básicas dentre outras, mas indispensáveis a qualquer processo onde a liberdade e a emancipação são prioridades e demandas em favor das camadas

\footnotetext{
${ }^{42}$ Palestra proferida durante o Seminário da ANPAE/RJ, em 12/04/16 em uma das conferências de abertura do evento.
} 


\section{RevistAleph}

menos favorecidas da população, inclusive pelos processos de avaliação das aprendizagens.

Voltando à entrevista, indagamos sobre as relações pedagógicas e sociais percebidas na escola. Sobre o tema, a pedagoga assim se colocou:

Eu encontrei aqui uma escola muito acolhedora. As diretoras estão sempre dialogando comigo, me deixando muito à vontade, dando dicas, porque sou nova como pedagoga e também com as professoras, eu fui muito bem recebida. E agente está sempre buscando dialogar de igual para igual, não tem esse desnível. A gente está sempre junto (...) nós estamos discutindo muito sobre avaliação. A gente tem muita liberdade de um ajudar o outro, de dar conselhos, pedir socorro quando precisa. Uma relação muito boa.

Este depoimento contém pistas importantes. Primeiramente, podemos observar que a direção da escola está atenta à formação continuada dos seus profissionais. A pedagoga traz saberes da docência, mas a condição de gestora do processo pedagógico é um caminho a desbravar. Outra pista que merece destaque é a questão da solidariedade entre pares e a dimensão positiva nas relações, que ela faz questão de destacar. Este movimento nos remete ao que Santos (2000) vai chamar de relações emancipatórias, como já discutimos anteriormente. Poderíamos considerar que há uma distribuição saudável de poder no contexto do campo de pesquisa.

A diretora poderia, como fazem muitas outras, reclamar da imaturidade profissional da pedagoga. Ao invés disso, traz para perto, orienta, auxilia demarcando a dimensão dialógica presente no processo de gestão democrática. Insistimos, indagando à pedagoga sobre a avaliação.

A gente tem feito o movimento de discutir avaliação... e não falamos só da avaliação da aprendizagem do aluno. Eu tenho feito um trabalho com elas de memórias e narrativas onde elas estão se lembrando de como eram como alunas, como que a avaliação foi importante ou não na vida delas. Então, tem professoras que falam que tem pavor de prova porque sofriam muita pressão. Então, nesse momento de resgate de memória delas, a gente vai pensando no nosso trabalho, também pensando no trabalho como um todo, na escola toda, na proposta de ciclo. Como entraria na avaliação da nossa proposta de ciclo. Se o regime seriado é melhor "pra" gente ou não. Temos feito muitas discussões bem bacanas.

É confortante observar que há escolas que se preocupam com a avaliação nessa dimensão. Uma discussão que ultrapassa a aprendizagem do aluno avança para a 
autorreflexão por meio de narrativas e entrecruza experiências (LARROSA, 2002) para pensar a prática pedagógica cotidiana a partir do que acontece e se passa com os atores sociais. A avaliação neste espaço ganha outro lugar no cotidiano escolar porque incorpora elementos novos como autoavaliação, criticidade, escuta com disponibilidade para o diálogo entre outros elementos ricos e potencializadores favoráveis aos avanços dos estudantes.

$\mathrm{Na}$ formação permanente dos professores, o momento fundamental é o da reflexão crítica sobre a prática. É pensando criticamente a prática de hoje ou de ontem que se pode melhorar a próxima prática, o próprio discurso teórico, necessário à reflexão crítica, tem de ser de tal modo concreto que se confunda com a prática. O seu "distanciamento" epistemológico da prática enquanto objeto de análise deve dela "aproximá-lo ao máximo". Quanto melhor faça essa operação, tanto mais inteligência ganha da prática em análise e maior comunicabilidade exercem em torno da superação da ingenuidade (FREIRE, 1996, p. 39).

Consideramos que é na iniciativa da jovem pedagoga que residem as reflexões de Larrosa e de Paulo Freire. Isto representa dizer que para pensar a avaliação, a pedagoga parte das realidades e das experiências que envolvem o grupo de professores, amplia saberes e conhecimentos. Forma, formando-se pedagoga neste emaranhado de acontecimentos para melhor compreender as complexidades presentes na dinâmica da avaliação. Este caminho leva aquele coletivo a se orientar pelas reflexões de Helal e Ribeiro (2014), no que diz respeito à avaliação quando sinaliza que

pensar na avaliação, também como um momento de metarreflexão da prática, um movimento escorregadio e revelador: revela saberes, ainda não saberes dos estudantes, mas revela da mesma forma - e talvez, sobretudo - percursos e percalços da prática pedagógica, ajudando os professores a repensar o próprio processo vivido com os alunos e alunas com os quais trabalham (HELAL \& RIBEIRO, 2014, p.148).

Então, continuamos nossa conversa com a pedagoga:

Eu acho que uma discussão que a gente acaba fazendo também, é avaliação que é padronizada. O sistema de avaliação nacional, por exemplo, que avalia da mesma forma que o Julia Cortines que "tá" no centro de Icaraí, que tem outra clientela, e aqui é o bairro de pior IDH da cidade, pior índice de desenvolvimento humano. Muitos analfabetos. Então, eu acho que avaliação, ela deveria considerar também, qual é o efeito que a escola tem na vida dessas crianças. 


\section{RevistAleph}

Porque no Julia Cortines eu encontrei alunos que eram filhos de pósdoutores, outros que eram filhos de empregadas que trabalhavam na região, mas que tinham acesso aos livros, além dos filhos das desempregadas. E aqui qual que é a realidade dessas crianças? De certo abandono, "né"? Porque muitas vezes os pais não dão nenhuma satisfação aos filhos. As crianças que vão pescar com os pais. Muitas vezes contam com a ajuda deles nos estudos em casa, porque os pais não tem conhecimento. Então, eu acho que uma avaliação pra elas potencializarem a escola, (...) ela tem que "tá" percebendo qual é a realidade da escola.

Problematizando a aplicação de avaliação externa, ela faz uma crítica coerente sobre a diversidade de atores sociais envolvidos nesse processo. Compara a realidade educacional dos alunos da própria rede municipal. Escolas localizadas em espaços geográficos diferentes podem oportunizar diferentes possibilidades de construção de conhecimento. Todos os estudantes podem aprender, mas as condições materiais, afetivas e econômicas podem interferir significativamente nesse processo e a pedagoga bem sinaliza para tal.

Como aponta Fernandes (2014, p. 121), “a pergunta avaliar para aprender deve ser feita também considerando as fortes políticas atuais de exames geradores de índices que ditam a qualidade da educação". E acrescenta:

\footnotetext{
Para compreender os efeitos dos testes e nos aprofundar na reflexão acerca das políticas educacionais, é fundamental observar e investigar o cotidiano das escolas. O que vem acontecendo nas escolas com a naturalização dos testes de larga escala? Seu projeto pedagógico se alterou? Os professores modificaram suas práticas? Os estudantes se reorganizaram a partir dos resultados? Os planejamentos se modificaram? Os tempos e espaços se alteraram? A formação docente sofreu mudanças, bem como a gestão? Inúmeras podem ser as perguntas e infinitas as respostas. (idem, p. 121)
}

Talvez essas sejam algumas das inquietações subentendidas na fala de Gisele. Ela se preocupa em garantir oportunidades iguais para os estudantes, mas há questões que estão para além do seu alcance. Sem contar que para além das escolas mencionadas, existem outras na rede municipal onde as condições de vida são ainda mais precárias.

Nesse sentido, as políticas de avaliação externa podem apresentar um caráter dualista. De um lado podem servir de diagnóstico, de outro podem funcionar como 


\section{RevistAleph}

prática de exclusão, visto que acabam oportunizando um processo perverso de ranqueamento entre escolas municipais, estaduais e federais. Processo este que desqualifica, desabona e interfere na avaliação que qualifica, liberta e emancipa.

São efeitos que se relacionam a um projeto de sociedade. As políticas educacionais relacionadas à performatividade, atribuindo prêmios aos docentes, impedem que outro projeto se imponha, qual seja: salários dignos e valorização da profissão" (idem, 121-2).

Nesses diálogos é possível perceber que a escola acolhe e apoia os profissionais e estudantes. Observamos ainda que a avaliação é uma preocupação geral. Embora existam sinais de uma dualidade: avaliar para mensurar e classificar ou utilizar a mesma estratégia para potencializar e emancipar. A escola está dividida entre as demandas do mundo contemporâneo e as reais necessidades de aprendizagem dos alunos. Dentre estas preocupações centrais está a questão da avaliação. E fica a pergunta emblemática: avaliar para quê?

Avaliação em larga escala ela tem uma importância, porque eu acho que ela dá uma visibilidade "pra" algumas escolas, mas ela não necessariamente retrata a realidade da rede municipal. Não necessariamente um IDEB ${ }^{43}$ alto significa que a qualidade do processo de aprendizagem daquela escola seja defasada. $E$ também tem muitas escolas que não acreditam nesse sistema, $e$ não investem nele, enquanto têm outras escolas que só focam o sistema de avaliação externa. Então, quando chega perto das avaliações investem nos simulados, como se tivesse preparando os alunos. E sobre o SAEN ${ }^{44}$, é o exame de Niterói?

Partimos então, para entrevistar a segunda pedagoga. Ela está na escola municipal, lócus da pesquisa há bastante tempo. Também trabalha na rede privada de ensino. Tem um conhecimento refinado sobre educação e uma experiência pedagógica e cultural vasta. Suas intervenções são críticas e reflexivas. Volta-se com maior facilidade para o segundo ciclo, mas não abandona o primeiro. É articulada, inteligente e tem uma relação aparentemente muito boa com as gestoras e com todos os profissionais da escola. Suas questões desafiam o grupo a pensar e se pensar. Conviver com ela foi uma experiência rica e interessante. Sua agilidade, presteza e capacidade de mobilização impressionaram.

\footnotetext{
${ }^{43}$ IDEB - Índice de Desenvolvimento da Educação Básica.

${ }^{44}$ SAEN - Sistema de Avaliação da Educação de Niterói.
} 
A entrevista com a pedagoga trouxe algumas reflexões interessantes. Formada em Psicologia, adentrou o mundo da educação como psicóloga escolar na rede privada de ensino. Seu envolvimento com as crianças despertou a curiosidade acerca dos processos de aprendizagem infantil. Esta postura a levou a cursar mestrado em Psicologia Cognitiva. Tal envolvimento oportunizou o acesso ao cargo de coordenadora pedagógica. Decidiu então se tornar estudante de Pedagogia na Universidade Federal Fluminense, onde pela primeira vez entrou em contato com a educação pública. Viveu um grande estranhamento durante a graduação, chegando a se sentir excluída, visto que sempre estivera envolvida com o ensino privado.

Formada, ingressou na rede municipal de educação de Niterói em 2010, para atuar como pedagoga e a primeira impressão, segundo seu depoimento, não foi nada sedutora. Em uma de suas primeiras vivências em escola, percebeu a contradição entre o discurso apresentado na universidade e a realidade do cotidiano escolar.

Eu ouvia dos professores, na universidade pública, que trabalhar na escola privada, na verdade, é trabalhar a serviço do capital $e$ trabalhar na escola pública era onde você teria possibilidade de transformação. E quando eu cheguei à escola pública, não foi essa impressão que eu tive, foi outra. Eu tive a impressão de que aquelas crianças que eu encontrei aqui estavam fadadas à alienação, à falta de acesso ao conhecimento e, portanto, aqui, eu via como um espaço de mais reprodução do que o espaço da escola privada, onde eu estava. Porque quando você possibilita uma educação libertadora mesmo dentro da escola privada que as pessoas criem uma visão de mundo e essa visão pode ser transformadora.

Conta-nos que iniciou sua trajetória profissional da rede pública enfrentando a insistente dualidade entre o valor do público e o privado. Embora tenha cursado uma universidade pública, aparentemente não conseguiu perceber as disputas teóricas e epistemológicas que confrontam a educação brasileira. Segundo ela, viveu situações muito duras na escola pesquisada que provocaram uma transformação coletiva, na qual estava incluída. Sobre sua relação profissional com os profissionais da escola, a pedagoga foca sua resposta na direção e aponta uma confortável situação de acolhimento nos seis anos de convivência.

Desde o primeiro momento eu me senti muito acolhida pela atual diretora. Ela tem algumas características que particularmente eu me identifico, ela é uma pessoa bem transparente... essa característica dela ser uma pessoa transparente, franca, direta, assertiva, então, 
isso eu acho muito positivo, procuro corresponder. Estou aqui para colaborar, e como a equipe tem um o propósito de fazer uma educação de qualidade, os objetivos são os mesmos. Então, as pessoas se afinam. Isso não significa que não haja divergências, já tive ideias diferentes das que foram implantadas, mas eu procuro ser bem democrática, se a maioria quer eu passo a querer também.

O depoimento da profissional nos remete às questões da gestão. Ao destacar a dimensão coletiva do trabalho e a tomada de decisões a partir da participação de todos que deliberam sobre situações diversas, as negociações consensuais, a pedagoga deixa mais indícios da tentativa de valorização dos princípios da gestão democrática materializados no cotidiano da escola. Este é um dado importante, pois uma das nossas buscas se centra na materialização de práticas concretas de gestão democrática no cotidiano da escola. Não como movimento cristalizado, hegemônico e ensaiado, mas como processo que vai se constituindo a partir do acolhimento, da interação, escuta e participação. Nesse sentido, a avaliação ganha um lugar redimensionado posto que esta se reconfigura, levando os atores sociais a refletirem sobre o papel que essa etapa pedagógica exerce no contexto escolar:

Eu acho que o sujeito está o tempo inteiro avaliando, é... e isso assim, é um processo inerente do ser humano. Portanto, eu acho que mais do que negar a avaliação, a gente deve encará-la e fazê-la da melhor maneira possivel, que eu acho que essa avaliação não é uma questão simples dentro da escola pública. Aí eu sigo a avaliação de aprendizagem, mas quando eu entrei na escola não havia nenhum ciclo de avaliação, nenhum, nenhum. Objetivamente, nenhum, mesmo os relatórios finais que eram preenchidos, eram impressões $e$ observações baseados em pouca metodologia, pouca sistematização. Então, era mais, o olhar subjetivo.

Temos novamente um olhar que foca a avaliação como um processo, mas também destaca a dificuldade de concretizá-la com justeza. Evidencia-se a necessidade de registros avaliativos mais cuidadosos. A pedagoga afirma que quando começou a trabalhar na unidade escolar os registros ofereciam dados precários sobre avaliação. Esta não é uma realidade restrita àquela unidade escolar. Como temos acesso aos registros avaliativos de outras escolas da rede municipal, temos de concordar que, em muitos casos, a observação procede. Este é um problema grave uma vez que estes registros revelam dados importantes sobre a aprendizagem dos estudantes. Como intervir nessa realidade frágil e inconsistente? 


\section{RevistAleph}

Nossa preocupação se sustenta na concepção de que, para alguns profissionais de educação, os registros avaliativos não têm importância, nem interferem na vida escolar dos estudantes. A pedagoga destaca o risco de que esta suposta espontaneidade possa ganhar uma aparência mais democrática. No entanto, considera tal iniciativa perigosamente excludente, posto que oculta referências importantes para intervenções pedagógicas futuras. A espontaneidade pedagógica interfere no compromisso com as aprendizagens dos estudantes, bem como o acesso aos saberes historicamente construídos, o que possibilitará novas construções e novos saberes. Seguindo a discussão, ainda destaca que:

acho que a avaliação é algo extremamente importante, acho que a avaliação dos alunos, a avaliação da equipe pedagógica, eu diria que a avaliação é um termo da área privada, mas é uma avaliação 360, né? Por exemplo, nós aqui aplicamos um questionário com os pais no final do ano, justamente "pra" saber deles o que acham da escola, o que a escola pode melhorar, eu acho que isso tudo ajuda a escola, a escola é um espaço dinâmico e precisa disso para se repensar.

Sua reflexão sinaliza para uma iniciativa de ampliação do foco da avaliação. Ela já não pensa apenas no processo de ensino e aprendizagem, mas destaca a necessidade de se pensar nas ações dos atores sociais envolvidos no processo educativo. Menciona inclusive a participação da comunidade escolar como possibilidade de reorganização e planejamento. Ela nos aproxima da urgência de práticas relacionadas à avaliação institucional como alternativa de desculpabilização do aluno pela ausência de sucesso na aprendizagem e distribui responsabilidades entre os demais envolvidos no processo educativo.

A rede municipal de Niterói vem empreendendo um esforço para construir um sistema de avaliação - Sistema de Avaliação da Educação de Niterói (SAEN), destinado a compreender a educação pública da cidade em maior profundidade. A pedagoga alegava desconhecer os fundamentos dessa ação. Abrimos esta breve reflexão sobre o SAEN, todavia, sem intenção de esgotá-la. Entendemos que a avaliação institucional se configura como uma ferramenta de relevância significativa frente aos atuais desafios sociais, políticos, econômicos e culturais demandados pelas complexidades deste tempo histórico com suas imprevisibilidades, incertezas e mobilidades (MORIN, 2002). 


\section{RevistAleph}

A entrevista se amplia e indagamos à pedagoga sobre a discussão que gira em torno da avaliação emancipatória e se ela percebe que a equipe pedagógica adota esta concepção. E temos as seguintes considerações:

Sim, considero emancipatória porque entendemos a avaliação com uma dupla função. Uma para situar o ponto de aprendizagem do aluno para criarmos estratégias de avançar e ir adiante ao processo do aluno. A outra função é porque permite delimitarmos a apropriação de conhecimento que, na minha perspectiva, é libertadora. Sem conhecimento, sem compreensão não se pode compreender o mundo. E tal conhecimento trata da aprendizagem formal, daquela que permite acesso as leituras de mundo, para que superemos a alienação.

Seu posicionamento revela uma pista importante relacionada ao que aprendemos com Barriga (2003) e Luckesi (2002) sobre a lógica do exame que ainda nos habita. Para Barriga o exame é um mero instrumento de medição que pouco ou nada contribui para o avanço dos estudantes. Esta defesa faz parte também das reflexões de Luckesi que, além de confrontar as práticas escolares fundadas em provas que pouco provam o conhecimento construídos pelos estudantes, ainda sinaliza para a importância da avaliação em sua dimensão diagnóstica, uma vez que pessoas são singulares, únicas e aprendem de formas diferenciadas. Nesse sentido, "alinhavar" esta discussão com os estudos recentes de Fernandes (2014), nos ajuda a enxergar melhor outros horizontes e possibilidades. Assim,

Considerando a complexidade do ato de ensinar e aprender, podemos compreender que muitas são as formas de conceber a avaliação e praticar a avaliação; desde a utilização de provas e testes, tendo-os como as únicas tarefas avaliativas legítimas, até formar a ideia de que todas a tarefas e trabalhos cotidianos são atividades de avaliação (FERNANDES, 2014, p.117).

A pedagoga reconhece nos fazeres da unidade escolar um trabalho comprometido com a emancipação dos alunos, principalmente no que diz respeito à avaliação da aprendizagem. Também conseguimos observar este movimento em diversos momentos que comparecemos para as entrevistas. Observamos várias práticas cotidianas que envolvem as gestoras, os funcionários administrativos, o pessoal de apoio e as professoras. Percebemos ainda que existe na escola 
compartilhamento de ideias e propostas, participação do grupo no processo decisório, escuta atenta aos responsáveis, dentre outras questões.

Não percebemos em nenhuma das nossas idas à escola posturas agressivas ou marcadas por assédio. Não houve gritos, brigas nem mesmo entre as crianças, embora soubéssemos de um ou outro caso de desentendimentos entre alunos, fruto das relações extraescolares que acabavam adentrando a vida escolar. Por várias vezes, assistimos a equipe pedagógica conversando e orientando alunos, professores e mesmo responsáveis, mas a atitude era comumente marcada pela firmeza, pela postura ética e pelo desejo de aprimoramento pessoal e profissional dos envolvidos.

Tais percepções nos remetem a alguns princípios e pressupostos da avaliação emancipatória (SAUL, 1995) posto que o que se apresentava naquele cotidiano não era somente uma preocupação com a transmissão de conhecimentos, conceitos e rendimento escolar (estes aspectos também se apresentavam de maneira relevante).Havia algo mais. Transparecia um cuidado com a formação humana, com as perspectivas de futuro, com a postura dialógica e emancipadora marcando as relações, consumando ainda que progressivamente, de certa forma, aquilo que Santos (2000) chama de relações emancipatórias.

Perguntamos também sobre seu olhar em relação à gestão da escola. Seu posicionamento assim se apresentou:

De uma maneira muito simples. Uso devido e adequado do $\mathrm{CEC}^{10} \mathrm{e}$ decisões compartilhadas. Gestão clara e transparente e pessoas que trabalham cumprindo suas obrigações e horários (...). Acredito que sim, não só esses dois aspectos mas todos os processos se articulam dentro do espaço. Problemas surgem e são resolvidos de maneira clara e rápida. Criamos afeto e, portanto, nos sentimos afetados pelo Lucia. \#todosomos/uciamaria.

Confirmando outros relatos, bem como alguns dos princípios que orientam a gestão democrática na escola municipal, a pedagoga se posiciona de forma clara e precisa. De personalidade forte e segura, pontua com precisão no olhar, aborda aspectos sobre a gestão da escola. Nosso diálogo traz contribuições significativas para refletirmos sobre as alternativas adotadas para a construção de outras práticas de

${ }^{10}$ CEC - Conselho Escola-Comunidade 


\section{RevistAleph}

gestão. Sinaliza para rupturas em processo que vão se consolidando gradativamente e vão dando outra roupagem ao cotidiano escolar.

Temos clareza de que nada se transforma da noite para o dia, que a inércia, as omissões e excessos nas estruturas, nos textos e nas mentalidades são impiedosas e fortes o suficiente para que outra concepção paradigmática possa emergir. No entanto, a presença de educadores inconformados e estudantes desafiadores representa um elo a mais da corrente que vai se constituindo em mais uma frente de luta contra os conservadorismos, autoritarismos e segregação tão presentes no contexto escolar. Diante de tais reflexões teóricas, é possível que se as pessoas quiserem assegurar e garantir um modo de vida democrático, precisam de oportunidades para descobrir o que significa este modo diferenciado de pensar sua materialidade, como pode ser vivenciado, a despeito de toda a complexidade que guarda em si, principalmente quando se trata de educação e escola.

Sousa (1997) esclarece que o envolvimento dos atores sociais no processo de transformação das práticas avaliativas demanda que todos sejam informados sobre inquietações, estudos e discussões que vem ocorrendo. Demanda ainda que sejam estimulados a criticarem e refletirem sobre o sentido da avaliação escolar. Os depoimentos da pedagoga, além de reafirmarem os aspectos teóricos já levantados, nos aproximam das reflexões da mesma autora que aponta o seguinte:

se contraponham à tendência que tem sido dominante. $\mathrm{O}$ emergir de uma nova concepção e prática de avaliação integram o conjunto de Ter-se o coletivo da escola como sujeitos da avaliação é condição que definições de natureza filosófica, pedagógica e administrativa de cada contexto escolar, resultando, portanto, em decisões coletivas. Decisões essas que implicam o confronto de posições que se manifestam, em relação à avaliação como condição para que se vivencie com transparência e responsabilidade a autoavaliação (SOUSA, 2014, p. 101).

Avançando na investigação, nos aproximamos do corpo docente. Uma das professoras sinalizou para um processo que considera significativo. Ela percebia um movimento dialógico e dialético no contato diário com as crianças. Observava um elemento diferencial, marcado por negociações constantes e pela habilidade de argumentar com os estudantes. Estes movimentos foram construindo uma relação de crítica, reflexão, lampejo de democracia, caminhos primeiros para a emancipação. A 


\section{RevistAleph}

turma não se assujeita (ADORNO, 1995), ao contrário, procura conquistar suas vontades, mas a professora força uma postura responsável e madura dos estudantes.

As interações e negociações eram fortes. Havia poder em jogo. Era a autoridade da professora frente aos desejos dos estudantes. Este processo nos leva ao construto anunciado por Santos (2000), que nos alerta para a existência de relações emancipatórias, para os jogos de poder atuando na sala de aula como alternativa de materialidade dessas relações no processo educativo. Um aspecto que nos chama a atenção é o fato de que os assuntos tratados na aula iam além do planejamento. As dúvidas que surgiam viravam objeto de estudo no momento em que surgiam e tal iniciativa, segundo a professora, não atrapalha o seu planejamento.

Essas discussões não são fáceis de serem realizadas, pois é no exercício cotidiano de conversar, debater e refletir que as aprendizagens de escutar o outro, de concordar ou discordar, trazendo seus modos de pensar e aprendendo a contra argumentar, vão acontecendo. As vozes infantis trazem o ruído e o barulho, compreendidos, muitas vezes, como "bagunça", como desordem. Mas é necessário acolher as narrativas infantis permeadas de seus modos singulares de ver e compreender o mundo, com suas lógicas que, com frequência, nós, adultos, ainda não conseguimos compreender seus sentidos de conhecer. (FERNANDES, 2014, p. 170).

A autora nos alerta para um aspecto significativo. A necessidade de escuta, de diálogo e interação se desejamos formar jovens e adultos mais humanizados e comprometidos com o mundo (FREIRE, 1996).

Responsabilidades compartilhadas. O trabalho coletivo é a mola que move uma escola que se pretende emancipatória. Fernandes (2014) afirma que através da avaliação os estudantes podem ser orientados a realizar trabalhos, localizar suas dificuldades e descobrir seu potencial, podendo assim redirecionar percursos de aprendizagem. Para a autora a avaliação pode buscar ainda uma participação ativa dos sujeitos em seus processos escolares de aprendizagem, construindo sua autonomia na vivência de práticas avaliativas emancipatórias que levem alunos a desenvolverem um papel ativo em seus processos de aprender e as decorrências desses.

Ao mesmo tempo esta dinâmica se fortalece quando as práticas de gestão ganham outro dimensionamento. Nesse sentido, vale considerar que tomada de decisões consistentes não pode ficar apenas no campo das ideias; precisa, sim, comprometer a ação gestora com a dimensão pedagógica no mesmo patamar que a 


\section{RevistAleph}

dimensão administrativa. Ação que zela para que os estudantes aprendam e tenham alternativas dignas de vida (profissão, trabalho, formação contínua), contribuindo para se "tornarem cada vez mais presenças no mundo" (FREIRE, 1997, p.72), o que representa um passo importante para a maior interação entre gestão democrática e avaliação escolar.

\section{REFERÊNCIAS}

ADORNO, Theodor. Educação e Emancipação. Rio de Janeiro: Paz e Terra, 1995.

BARRIGA, Angel Diaz. Uma polêmica em relação ao exame: In: ESTEBAN, Maria Teresa (Org.). Avaliação: uma prática em busca de novos sentidos. Rio de Janeiro: DP\&A, 2003, p. 51-82.

BASTOS, J. B. (org.). Gestão Democrática. R io de Janeiro:DP\&A, 2000.

DOURADO, Luiz Fernandes. Gestão da educação escolar. Brasília:UNB-Centro de Educação a Distância, 2006. Disponível em: portal.mec.gov.br/seb/arquivos/pdf/profunc/06_gest_edu_esc.Acesso em 12/01/2016.

. Gestão da educação escolar. 4 ed. revisada e atualizada. Cuiabá:Universidade Federal de Mato Grosso/Rede e-Tec Brasil, 2012. Disponível em: portal.mec.gov.br/docman/setembro-2012.../11591-gestaodaeducacaoescolar140912. Acesso em março de 2016.

FERNANDES, Claudia de O. Avaliação das aprendizagens - sua relação com o papel social da escola. São Paulo: Cortez, 2014.

FREIRE, Paulo. Professora sim, tia, não - cartas a quem ousa ensinar. São Paulo:Olho D’Água, 1997.

. Pedagogia da Autonomia - saberes necessários à prática educativa.

30ed. Rio de Janeiro: Paz e Terra, 1996.

HELAL, Igor e RIBEIRO, Tiago. Possibilidades e desafios: percursos e percalços de uma prática avaliativa emancipatória. In: FERNANDES, Claudia de O.(Org.) Avaliação das aprendizagens - sua relação com o papel social da escola. São Paulo: Cortez, 2014.

HOFFMANN, Jussara. Avaliação - mito e desafio: Uma perspectiva construtivista. 32. ed. Porto Alegre, 2003.

LARROSA, J. B. Notas sobre a experiência e o saber de experiência. Jan/Fev/Mar/Abr 2002 № 19. Disponível em: www.scielo.br/pdf/rbedu/n19/n19a02.pdf 
LUCKESI, Cipriano. Avaliação da aprendizagem escolar. 13 ed. São Paulo:Cortez, 2002. MORIN, Edgar. Os sete saberes necessários à educação do futuro.2ed. São Paulo:Cortez, 2002.

NAJJAR, J. Gestão democrática da escola, ação democrática e emancipação humana. In; Revista Movimento, n. 13, maio de 2006.

PARO V. H. Administração escolar - Introdução e Crítica. São Paulo: Cortez, 2008a. . Gestão democrática da escola pública. 3ed. S. Paulo: Ática, 2008b. . Escritos sobre educação. S. Paulo: Xamã, 2001.

PERRENOUD, Ph. Avaliação. Da Excelência à regulação das aprendizagens. Porto Alonra. Artmed Editora, 2000.

SANTOS, Boaventura de Souza. A crítica da razão indolente - contra o desperdício da experiência. São Paulo:Cortez, 2000.

SANTOS, Boaventura de Souza. Um discurso sobre as Ciências. São Paulo:Cortez, 1987. SAUL, Ana Maria. Avaliação emancipatória: desafio à teoria e à prática de avaliação e reformulação do currículo. 3. ed. São Paulo:Cortez, 1995.

SOUSA, Sandra Zákia. Avaliação na escola básica: controvérsias e vicissitudes de significados. In: FERNANDES, Claudia de O. Avaliação das Aprendizagens - sua relação com o papel social da escola. São Paulo:Cortez, 2014.

. Avaliação escolar e democratização: o direito de errar. In: AQUINO, J. G. (org). Erro e fracasso na escola: alternativas teóricas e práticas. São Paulo:Summus, 1997.

SOUZA, Gloria M. Anselmo de; CARNEIRO, Waldeck. Reorganização do Sistema de Ciclos na Rede Municipal de Educação de Niterói (RJ) (2005-2008): primeiras aproximações. In: GOMES, Júlio César e CHAFFEL, Sarita Léa (orgs). Currículo: limites e possibilidades. Rio de Janeiro: Centro de Estudos de Pessoal, 2010.

SPÓSITO, Marília Pontes. Educação, gestão democrática e participação popular. In: BASTOS, J. B. (org.). Gestão Democrática. Rio de Janeiro:DP\&A, 2000. 